\title{
Cysteine in Calf-Thymus Histones
}

\author{
By D. M. P. PHILLIPS \\ Chester Beatty Research Institute, Institute of Cancer Research: \\ Royal Cancer Hospital, London, S.W. 3
}

(Received 19 May 1965)

\begin{abstract}
1. Calf-thymus histones contain cysteine, which is present almost entirely in the arginine-rich fraction F3 to the extent of about 1 mole in $15000 \mathrm{~g}$. weight of the histone. 2. The cysteine in fraction F3 is readily available to thiol reagents and the protein yields an approximately equivalent amount of cysteic acid on oxidation with performic acid.
\end{abstract}

Felix \& Rauch (1931) observed a positive nitroprusside reaction in the proteins prepared by direct extraction of thymus tissue with hydrochloric acid, which they concluded was a property of the native histones. Daly \& Mirsky (1954-55) reported cysteine to be absent in the very lysine-rich histones but present to the extent of $0.28 \mathrm{~mol} . / 100$ atoms of nitrogen in the arginine-rich histones (at that time this latter term embraced all the histones that were precipitated from aqueous solution at $\mathrm{pH} 10 \cdot 6$ ). Cystine was also found in small amounts in hydrolysates of whole calf-thymus histones by Crampton, Moore \& Stein (1955), and in the histone chromatographic fraction B by Crampton, Stein \& Moore (1957), this fraction being one with a slight molar excess of lysine over arginine. Further evidence for the presence of cysteine or cystine was found during the hydrazinolysis of calf-thymus histone fractions (Phillips, 1963). Blazsek \& Bukaresti (1964) found polarographically that the fraction F3 of chicken-erythrocyte histones eluted from CMcellulose by $0.02 \mathrm{~N}$-hydrochloric acid, and no other fraction, contains thiol groups. Deakin, Ord \& Stocken (1963) observed with rat thymus that $70 \%$ of the thiol groups of the nuclei were associated with the arginine-rich histones (prepared by the method of Daly \& Mirsky, 1954-55) and none was associated with the lysine-rich histones. Moreover, with rat liver as the source, Marsh, Ord \& Stocken (1964) found thiol groups associated with two histone fractions separated by electrophoresis in polyacrylamide gel.

During the fractionation of the histones carried out in recent years in this Laboratory (see Johns, 1964), cysteic acid and occasionally cystine have been observed in hydrolysates of the fractions, and the yields showed that fraction F3 (the argininerich histone with a lysine/arginine ratio about 0.8 and an alanine $N$-terminal group) was the only one containing an appreciable amount. This frac- tion was also the only one giving a positive qualitative nitroprusside test, indicating that part of the cysteic acid and cystine originated from cysteine. The experiments of Stocken and his colleagues and of Blazsek \& Bukaresti mentioned above have prompted a closer re-examination of the calfthymus histone fractions.

\section{MATERIALS AND METHODS}

The histone fractions F1, F2al, F2a2, F2b and F3 were prepared from fresh frozen calf thymus by the methods of Johns (1964) and Phillips \& Johns (1965). The cystine+ cysteine content was determined as cysteic acid after oxidation of the proteins with performic acid (Moore, 1963). After $4 \mathrm{hr}$. oxidation, the samples were diluted with water at $0^{\circ}$, frozen and freeze-dried before hydrolysis. Amino acid analyses were carried out by the method of Moore, Spackman \& Stein (1958) with amino acid analysers. The samples were hydrolysed in $6 \mathrm{~N}-\mathrm{HCl}$ at $110^{\circ}$ for $22 \mathrm{hr}$. under $\mathrm{N}_{2}$ in sealed tubes or, more recently, by the technique of Crestfield, Moore \& Stein (1963). Thiol groups were estimated by the method of Ellman (1959) with di-(2-carboxy3-nitrophenyl) disulphide. The reagent was obtained from R. N. Emanuel Ltd., London. Tris buffers are as suitable as phosphate, but borate buffers inhibit the reaction of thiol groups with this reagent.

\section{RESULTS}

Table 1 shows the values of cysteic acid and cysteine obtained with the histone fractions. The thiol values reached their maxima within $2 \mathrm{~min}$. of adding the Ellman reagent and were virtually unaltered in samples that had been left for $2 \mathrm{hr}$. in 4 M-urea beforehand. The presence of cysteic acid in the hydrolysates of some of the histone fractions both before and after oxidation with performic acid was also demonstrated by finding DNP-cysteic acid in the products formed by coupling the hydrolysates with 1-fluoro-2,4-dinitrobenzene.

The use of perchloric acid in one of the methods for the preparation of the histone fractions (Johns, 
Table 1. Cysteine and cysteic acid content of histones

The cysteic acid values were obtained from total amino acid analyses of the oxidized proteins after hydrolysis in $6 \mathrm{~N}-\mathrm{HCl}$ for $22 \mathrm{hr}$. at $110^{\circ}$ under $\mathrm{N}_{2}$. The cysteine determinations on the intact proteins have been corrected for $\mathrm{HCl}$ and water content to make them comparable with the cysteic acid values. Determinations of total N on 14 of the preparations indicated that $\mathrm{HCl}$ and water accounted for about $18 \%$ by weight. In parentheses are the numbers of different preparations of each fraction tested.

$\begin{array}{ccc}\begin{array}{c}\text { Histone } \\ \text { fraction }\end{array} & \begin{array}{c}\text { Cysteine } \\ (\mu \text { moles/g. of protein) }\end{array} & \begin{array}{c}\text { Cysteic acid } \\ (\mu \text { moles/g. of } \\ \text { protein oxidized } \\ \text { with performic acid) }\end{array} \\ \text { F1 } & 3-10(3) & 8-20(3) \\ \text { F2al } & 4-13(5) & 14-18(3) \\ \text { F2a2 } & 4-14(3) & 12-23(3) \\ \text { F2b } & 8-24(4) & 24-36(4) \\ \text { F3 } & 50-82 \text { (average 68*) } & 77-90(\text { average 82*) }\end{array}$

* Corresponding to 0.75 mole of cysteine and 0.9 mole of cysteic acid respectively/ 100 moles of all amino acids in fraction F3.

1964) did not alter the thiol content of the F3 fraction obtained. With some samples of fraction F3, turbidity, presumably due to aggregation, appeared in the phosphate buffer at $\mathrm{pH} 7 \cdot 4$ or $\mathbf{8 \text { , }}$ and urea was added to obtain clear solutions for reading.

Other experiments have been done to throw more light on the nature of the thiol groups in fraction F3. In 0.01 N-hydrochloric acid solution they are stable, losing only $10 \%$ in $24 \mathrm{hr}$. at room temperature, whereas at $\mathrm{pH} 5$ or 6.5 there is a $50 \%$ loss in $24 \mathrm{hr}$. and at $\mathrm{pH} 8$ or 9.2 a similar loss in $19 \mathrm{hr}$. The product of the loss of thiol groups has not been established. When the protein was digested

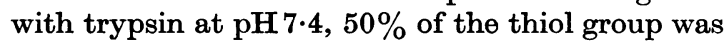
lost in less than $2 \mathrm{hr}$., i.e. at a rate comparable with that of reduced glutathione under the same conditions. The insoluble precipitate formed during the degradation with trypsin (Phillips \& Simson, 1962) contained over $70 \%$ of the cysteinyl-peptides. This was shown by the tryptic digestion of performic acid-oxidized fraction F3 and analysis of the soluble and insoluble parts for cysteic acid.

The thiol groups are readily accessible to $N$. ethylmaleimide and to $\mathrm{Hg}^{2+}, p$-chloromercuribenzoate, iodoacetate, iodopropionate and 4-(iodoacetamido)salicylate ions, as indicated by the loss of both nitroprusside reaction and reaction with the Ellman reagent after recovery of the treated protein.

\section{DISCUSSION}

Table 1 shows that fraction F3 is the only calfthymus histone fraction containing an appreciable quantity of cysteine and that this amino acid probably accounts for all the thiol groups in the protein and for all the cysteic acid found in the performic acid-oxidized protein. The oxidation of the thiol groups during the acid hydrolyses was due to oxygen still left in the system, and more cystine and less cysteic acid was found when the chilled protein solutions were evacuated by the method of Crestfield et al. (1963) before hydrolysis. No evidence of the presence of cysteine was found in the total amino acid analyses of the histones. If it were present it would be included in the proline estimation, since these two amino acids are inseparable under the conditions of elution used in the amino acid analysers.

The presence of a small amount of cysteine in all the other fractions requires some explanation. At least an equivalent amount of cysteic acid was found in the hydrolysates of the performic acidoxidized fractions. Studies by Johns (1964, and unpublished work) have shown that both fractions F1 and F2b normally contain small amounts of proteins with a high content of aspartic acid and glutamic acid (20-30 moles $/ 100$ moles), and hydrolysates of some of these have been shown to contain about Imole of cysteic acid/100moles (equivalent to $87 \mu \mathrm{moles} / \mathrm{g}$. of protein). Further, Murray (1964) suggests, from peptide studies, that fraction Fl (the very lysine-rich histone) may have many components. It may thus contain a subfraction with cysteine in it. Alanine accounts for about $15 \%$ of the $N$-terminal groups of fraction $F 2 b$ and, if this is due to the presence of F3 (since alanine is the characteristic end group of fraction F3; Johns, Phillips, Simson \& Butler, 1960; Johns, 1964), it would account for about half of the thiol groups found in fraction F2b. It is probable that fractions F2a1 and F2a2 also contain some fraction F3, since they still have a small proportion of alanine $N$. terminal groups. On the other hand, fraction F3 was also found to contain some acetyl groups (Phillips, 1963), which is due in part to the presence of some fraction F2a2. It also shows complexity on starch-gel electrophoresis (Johns, Phillips, Simson \& Butler, 1961) and no conclusion can yet be drawn as to whether cysteine is present in all components of this fraction. The average cysteine content of $68 \mu$ moles/g. in fraction F3 (see Table 1 ) is equivalent to $0 \cdot 75 \mathrm{~mole} / 100 \mathrm{moles}$ of all amino acids present, which corresponds to 1 mole of cysteine in $15000 \mathrm{~g}$. weight of protein. This is in excess of the $N$-terminal alanine content of this histone (1 mole/ 16000-19000g. weight; Phillips, 1963), implying that some component of fraction F3 may have more than one thiol group $/ \mathrm{mol}$. No special function of the thiol group in histone F3 is known, but its proximity to DNA and accessibility to thiol reagents make it especially interesting. The presence of the cysteine mainly in the insoluble part 
of the tryptic digest of fraction F3 indicates that it is in the non-basic portion of the protein and may thus be in one of the larger loops bulging out from adjacent phosphate groups in the nucleohistone complex (see Phillips, 1964).

I thank Professor J. A. V. Butler, F.R.S., for his encouragement, and $\mathrm{I}$ am indebted to Miss $\mathrm{P}$. Simson and Mrs D. Purkiss for many amino acid analyses and to $\mathrm{Mr} \mathrm{D}$. Power for the preparation of many of the histone fractions. This work has been supported by grants to the Chester Beatty Research Institute (Institute of Cancer Research: Royal Cancer Hospital) from the Medical Research Council and the British Empire Cancer Campaign for Research, and by the Public Health Service Research Grant no. CA-03188-08 from the National Cancer Institute, U.S. Public Health Service.

\section{REFERENCES}

Blazsek, V. A. \& Bukaresti, L. (1964). Experientia, 20, 369. Crampton, C. F., Moore, S. \& Stein, W. H. (1955). J. biol. Chem. 215, 787.

Crampton, C. F., Stein, W. H. \& Moore, S. (1957). J. biol. Chem. 225, 363.

Crestfield, A. M., Moore, S. \& Stein, W. H. (1963). J. biol. Chem. 238, 622.
Daly, M. M. \& Mirsky, A. E. (1954-55). J.gen. Physiol. 38, 405.

Deakin, H., Ord, M. G. \& Stocken, L. A. (1963). Biochem. $J .89,296$.

Ellman, G. L. (1959). Arch. Biochem. Biophys. 82, 70.

Felix, K. \& Rauch, H. (1931). Hoppe-Seyl. Z. 200, 27.

Johns, E. W. (1964). Biochem. J. 92, 55.

Johns, E. W., Phillips, D. M. P., Simson, P. \& Butler, J. A. V. (1960). Biochem. J. 77, 631.

Johns, E. W., Phillips, D. M. P., Simson, P. \& Butler, J. A. V. (1961). Biochem. J. 80, 189.

Marsh, W. H., Ord, M. G. \& Stocken, L. A. (1964). Biochem. $J .93,539$.

Moore, S. (1963). J. biol. Chem. 238, 235.

Moore, S., Spackman, D. H. \& Stein, W. H. (1958). Analyt. Chem. 30, 1185.

Murray, K. (1964). In The Nucleohistones, p. 21. Ed. by Bonner, J. \& Ts'o, P. O. P. San Francisco: Holden-Day Inc.

Phillips, D. M. P. (1963). Biochem. J. 87, 258.

Phillips, D. M. P. (1964). In The Nucleohistones, p. 46. Ed. by Bonner, J. \& Ts'o, P. O. P. San Francisco: HoldenDay Inc.

Phillips, D. M. P. \& Johns, E. W. (1965). Biochem. J. 94, 127.

Phillips, D. M. P. \& Simson, P. (1962). Biochem. J. 82, 236. 